\title{
Conceptual Framework for a Heuristics Based Methodology for Interface Evaluation of Educational Games
}

\author{
Hasiah Mohamed@Omar \\ Faculty of Computer and Mathematical Sciences, Universiti Teknologi MARA (UiTM) \\ Dungun Campus, 2300 Dungun, Terengganu, Malaysia \\ $\&$ \\ Faculty of Information Science and Technology, Universiti Kebangsaan Malaysia (UKM) \\ 43600 Bangi, Selangor, Malaysia \\ Tel: 60-9840-3835 E-mail: hasia980@tganu.uitm.edu.my \\ Azizah Jaafar \\ Faculty of Information Science and Technology, Universiti Kebangsaan Malaysia (UKM) \\ 43600 Bangi, Selangor, Malaysia \\ Tel: 60-3-8921-6811 E-mail: aj@ftsm.ukm.my
}

\begin{abstract}
The use of educational game in teaching and learning is increasingly relevant trend. Interface and usability are common elements in games development and important elements for evaluation purposes. This study is aiming to develop a methodology for heuristics based formative usability evaluation that can be used to evaluate interface of educational game. The methodology includes set of evaluation questions for different types of evaluators which are expected to optimize the use of resources regarding the online evaluation tool. The methodology is intended for the evaluation of educational games during its development process.
\end{abstract}

Keywords: Heuristics based, Playability, Evaluation, Heuristics Evaluation

\section{Introduction}

Usability is a one of the main and core concepts that have emerged from the human-computer interaction (HCI) field. There are various definitions of usability, amongst them are "the capability to be used by humans easily and effectively" (Shackel, 1991), "quality in use" (Bevan, 1995) and "the effectiveness, efficiency, and satisfaction with which specified users can achieve goals in particular environments" (ISO., 1998). Widely used definition of usability is based on definition by International Organization for Standardization (ISO) "the extent to which the product can be used by specified users to achieve specified goals with effectiveness, efficiency, and satisfaction in a specified context of use" (ISO., 1998). Based on various definitions, researchers have developed various technique and criteria to evaluate usability and one of the commonly use technique is Heuristic Evaluation (HE).

$\mathrm{HE}$ is a discount evaluation method commonly used to find usability problems at different development stages of a product. Heuristics are design guidelines which serve as a useful evaluation tool for both product designers and usability professionals (Nielsen, 1994). In the software productivity industry, heuristics have typically been used to evaluate the usability of interfaces (Nielsen, 1994). Heuristic evaluation involves a small number of evaluators inspecting a system according to heuristics or guidelines that are relevant for the system. Heuristic evaluation is a light-weight process that can be cheap, fast, and easy to apply in evaluation process. It can be used both in design and evaluation phases of development and can even be applied to paper-based designs before the first working prototype is created. HCI studies showed that using five evaluators may be enough to find most usability problems, adding more would reduce the benefit to cost ratio, and suggested that three may suffice (Rollings A., 2003). The HE technique has been emerged from evaluation of software (system and products) to one of the most popular applications nowadays which is games.

A number of games based application have been developed in this decade since the realism for the function of computer games and simulation in varied areas such as education, training, medical and lot more. As education increasingly use computer and web based application such as eLearning and games in their learning process 
either directly or indirectly, attention should be focused on ensuring design of the interface itself in order to help users not to make any errors (Pagulayan, 2003).

Games have various types varies from Arcade \& Action, adventure, Computer Role Playing (CRPG), simulation, building, war, sports, puzzle and educational (Gussin, 1995). Kasvi (Kasvi, 2000) lists five categories of games that are actions, sports, role playing, strategy and simulation. Definitions of games are various and among that are Crowford (Crawford, 1984) defines game as a closed formal system that subjectively represents a subset of reality. Other researchers define computer games as an activity that contains some or all of the following elements: rules, goals, challenges, fantasy, mystery, curiosity, competition, and skill (Garris, 2002) and (Randel, 1992). Computer games provide a good environment for learning and teaching. Educational software games aim at increasing the students' motivation and engagement while they learn. Educators need to realize that the factors of educational games should be on learning by playing not on teaching via games (Kiili, 2005). Hence, from the review of the literature, it can be concluded that it is essential to conduct interface evaluation for educational games in order to assist learners in their learning.

\section{Methodology}

Heuristics are designed to evaluate the user interface of the application covers from different types of application towards one of the commonly use applications nowadays that is games applications. The main concern of the evaluation is to find out how users can achieve their goal easily and efficiently. Probably, the most commonly used usability heuristics are those originally developed by Nielson and Molich (Nielsen, 1990). Later, HE has been modified to suit with other types of applications and nowadays there is a heuristics that focus on playability of the games. This heuristics are known as Playability Heuristics Evaluation (HEP).

\subsection{Heuristics Evaluation}

Heuristic evaluation (HE) is a usability engineering method "for finding usability problem in user interface design by having a small set of evaluators examine the interface and judge its compliance with recognized usability principles (the "heuristics") (Rollings, 2003). This method uses evaluators to find usability problems or violations that may have a deleterious effect on the user to interact with the system. Typically, these evaluators are experts in usability principles, the domain of interest, or both (so-called "double" experts). Nielsen and Molich (1990) described the HE methodology as "cheap," "intuitive," "requires no advance planning," and finally, "can be used early on in the development process." Often it is used in conjunction with other usability methodologies to evaluate user interfaces (Gussin, 1995).

Furthermore, HE's utility lies in its ability to rapidly find more usability problems, including more of the major problems, compared to other methods of evaluation (Kasvi, 2000). By evaluating the interface in the development phase, it is possible to identify design flaws. Finding these flaws earlier, rather than later, reduces subsequent usability errors, which may be more costly and prohibitive to rectify. Indeed, use of the HE methodology is ideal in the spiral or iterative development environment commonly found in the systems design industry.

\subsection{Playability Heuristics Evaluation}

In term of research in games usability, Malone (Malone, 1980) created the first heuristics to evaluate educational games. Faderoff (2002) has created a list of heuristics based on her study at a game development company. Later in 2004, Desurvire et. al (2004) has created the heuristics that are best suited to evaluate general issues in early development phase with prototype or mock-up (Crawford, 1984).

The HEP heuristics were based on the current literature and reviewed by several playability experts and game designers. The playability evaluator performed the Heuristic Evaluation for Playability (HEP) while focusing on how each heuristic was supported or violated and then defined the playability issue. Alternative solutions for resolving the playability issues were generated by both the evaluator and the game designer.

\subsection{Games}

Various definitions of games have been highlighted and amongst them are; "A game is a set of activities involving one or more players which has goals, constraints and consequences. A game is rule-guided and artificial in some respect. A game also involves some aspects of a contest or a trial of skill or ability, even if the contest is with oneself" (Dempsey, 1997),. The goals of software productivity are to make the software interface easy to learn, use, and master, and somewhat oppose design goals for games, usually characterized as "easy to learn, difficult to master" (Malone, 1982).

Games differ from utility software in some key characteristics. In games, the purpose is to have fun and enjoy 
playing the game. Learning to play the game, solving problems, or discovering new things is part of that experience. Moreover, in a game, the players do not know in advance what to expect. Game designers have created the game content and defined goals that the players must achieve. Playing a game is not straightforward either, but it is challenging, and the player needs to work towards goals.

Therefore, applying general usability heuristics in game evaluations is not sufficient and using only them would leave many important aspects of the game unprocessed (Federoff, 2002). There is a need to have specific heuristics that focus on games and other related issues in game design and development. Usability in games deals with two major issues. Firstly, interface design that offers the player an intuitive and easy way to control the game and secondly, the game design that ensures the balance between the players' ability and the challenge of the game that enables the experience flows (Csikszentmihalyi, 1975).

\subsection{Educational Games}

Games attract many people in term of usage in education. Naturally, Games may have an academic characteristic because of its involvement directly or indirectly in learning process. Educational games is one of the games types and genre that being discussed in term of the relevance and potential in education. Researchers argue regarding positive and negatives effects of games in education (Setzer, 2000), (Mary, 2007), (Gee, 2003).

A shift from pure entertainment to educational tool has emerged in recent times. The medium of educational games provides an opportunity for teachers to introduce educational and playful elements into the learning environment. As computer games are being adapted to the education system, the issue of classification and education elements needs to be brought to attention.

Usability issues play an important factor in order to determine specific educational games that can be used in formal education systems. Game usability, game interface, game play, game mechanics and game narrative need to be taken seriously in order to make sure the educational games use able to help students in their learning process.

\section{Research Issue}

Nielsen (1994) developed a list of heuristics that were aimed for use in productivity software. Software productivity studies by Desurvire, et al. (1994) demonstrated the effectiveness of these heuristics when combined with user studies. In game development, there is a need to develop a corresponding set of heuristics. Thus far, game heuristics have been developed by several individuals, groups, and professionals in the game industry and researchers in the HCI community.

Games heuristics started in 1982 when (Malone, 1982) constructed a list of heuristics for instructional games. Later in 2002, (Federoff, 2002) compiled a list of game heuristics from a case study at a game development company and compared them with current game industry guidelines and J. Nielsen's heuristics from 1994. Federoff (2002) identified 30 game heuristics and 24 fit into one of Nielson's heuristics and out of ten of those, fourteen were interface issues. Ten (10) Nielson heuristics and how it related in evaluating game usability are:

- Nielsen's Heuristic 1: Visibility of System Status

This heuristic applies to games, typically through score and/or level information.

- Nielsen's Heuristic 2: Match between the system and the real world

Games do not necessarily need to relate to the real world since they can be completely fantasy based.

- Nielsen's Heuristic 3: User Control and Freedom

Nielsen's third heuristic has to do with offering an "undo" function which is not relevant to games, but the concepts of user control and freedom are still important to game design.

- Nielsen's Heuristic 4: Consistency and Standards

The game user interface, as with all interfaces, should be consistent throughout industry standards.

- Nielsen's Heuristic 5: Error Prevention

In general, preventing errors requires careful usability testing.

- Nielsen's Heuristic 6: Recognition rather than recall Instructions for the system should be retrievable within the game, though quite often games are built with the intention to teach skill early in game play so that instruction is unnecessary.

- Nielsen's Heuristic 7: Flexibility and efficiency of use Games should be able to be played by players of different skill levels. Often this flexibility is provided with variable difficulty levels.

- Nielsen's Heuristic 8: Aesthetic and minimalist design Game controls and on-screen interface should be simple and non- intrusive to provide easy access to the 
game environment.

- Nielsen's Heuristic 9: Help users recognize, diagnose, and recover from errors

Error messages are not necessary during game play because commands are made through physical actions instead of syntax and results of actions are obvious and can be reversed easily.

- Nielsen's Heuristic 10: Help and documentation

Help needed to engage in game play should be primarily displayed through a tutorial. Smaller help items can be offered through the interface of the game.

In 2002, Järvinen, et. al. developed a theoretical tool for evaluating playability of games trough studying such notions and concepts as 'optimal experience', 'playability' and 'gameplay'. Another attempt was by Desurvire et. al. (2004) that has created heuristics that are best suited for evaluating general issues in early development phase with a prototype or mock-up. Table 1 shows heuristics for evaluating Playability.

\section{Conceptual Framework For Understanding Usability Factors Affecting Educational Games}

Several researchers identified different categories of games. The categories were also associated with usability issues in the games that have been evaluated in order to highlight the categories. Clanton (Clanton, 1998) highlighted three different usability issues which are: game interface - is the device through which the player interacts with the game, game mechanics - are the physics of the game, which are developed through a combination of animation and programming and game play - is the process by which the player reaches the goal of the game.

On the other hand, Desurvire et. al. (2004) emphasis on four game heuristic categories and it can be defined as the following: game play is the set of problems and challenges a user must face to win a game; game story includes all plot and character development; game mechanics involve the programming that provides the structure by which units interact with the environment; and game usability addresses the interface and encompasses the elements the user utilizes to interact with the game (e.g. mouse, keyboard, controller, game shell, heads-up display).

Key factors for game design also discussed by Song \& Lee (Seungkeun Song and Joohyeon Lee., 2007) and they derived key factors through a usability evaluation and a review of literature relevant to computer game design and HCI. Key factors for game design and broadly divided them into four subcategories; 'Game Interface' includes such factors as feedback, metaphor, control, consistency, recognition, flexibility, aesthetics \& minimalist design, help, affordance, and natural mapping., 'Game Play' involves factors such as goals, learning, rewards, challenges, pace \& pressure, re-playability, empathy, fairness, difficulty, balance, perceptual-motor skill., 'Game Narrative' consists of embedded narratives, evocative space, emergent narratives, enacting stories, interaction between gamers and the narrative, curiosity, and modeless., and 'Game Mechanics' comprises factors including immediate display, physics, and vividness.

According to Desurvire et. al. (2004), Clanton (Clanton, 1998) and Lee \& Song (Seungkeun Song and Joohyeon Lee., 2007), one of the commonly highlighted game heuristics categories is game usability (game interface). This explains the importance of usability and interface study in games design and development.

\subsection{The Usability Factors Affacting Educational Games Usability}

The list of factors to be investigated in this research has been compiled from various studies and includes:

1) Interface issues: characteristics of the educational games that have an effect on its usability. The interface issues include the following factors: consistency, interactivity, navigation, pleasant to use, screen design,

2) Pedagogical issues: characteristics that facilitate learning. The pedagogical issues may include: motivation, learners control, clear goal and objective, added value for learning, immediate feedback, player control and challenge.

3) Content issues: clear goal and objectives, feedback, realiable content, clear and understandable structure and engaging materials.

4) Multimedia issues: characteristics of the educational games that consist of multimedia elopements and have an effect on its usability may include: usage of text, animation, audio, image and video, multimedia presentation and suitability of multimedia used

5) Playability issues: the game study support the game play and it is meaningful, challenge, strategy and pace in balance, player is in control and players see the progress in the game and can compare the result.

\subsection{The Evaluators}

This methodology involves different types of evaluators/users (terms used interchangeably) in evaluating the selected educational games. Real users refers to the users who is going to use the educational games once the 
development process is finish and being distribute for the users. Surrogate users are users who involves directly and indirectly in development and usage of educational games. Parents and teachers consider as surrogate users that will be using questionnaire in order to comments and suggestion improvement for selected educational games whilst HCI experts and games developers will be considered as expert and they will be using different set of questionnaire that related to heuristics based. Involvement of different types of users in evaluation process is one of the options to get various comment and suggestion from evaluators. This may help in improvement and enhancement process of educational games so that the specific objectives of the development can be achieved.

\subsection{The Heuristic - Playability Heuristics for Educational Game (PHEG)}

Details criteria and description for each of the issues are highlighted in Table 2. The development of initial PHEG will focused details on each of the issues and evaluation of the PHEG will be conducted with suitable and experience expert in specific area, for example expert from educational background will evaluate the details of the heuristics of pedagogical and the subject matter expert will evaluate details of the heuristics of content.

\section{Development of Heuristics Based Methodology for Evaluation of Educational Games}

\subsection{The Methodology}

The methodology involve in this study will be a heuristics based set of questions that can be use in evaluating usability of the interface for educational games. The methodology will be developed in five steps.

- Step 1: Develop a questionnaire that addresses the usability factors that are validated in the survey. Each factor (five issues: interface, pedagogical, content, multimedia and playability) might require two or more questions.

- Step 2: Identify suitable evaluators, real user and surrogate users. Surrogate users may involve parents, teachers, games developers and expert (HCI).

- Step 3: Define the guideline in conducting usability evaluation

- $\quad$ Step 4: Specify steps in evaluation process.

- Step 5: Define the guidelines for reporting of usability defeats and recommendation for future enhancement.

\subsection{The Prototype}

The methodology will be implemented in an online system (prototype) that functions to collect specific errors or flaws detected by the evaluators. The prototype will be available online and include: (a) different interface (5 interfaces) and set of questions for different users (evaluators); (b) 3 databases to store evaluation questions, comments and recommendation and evaluators profile. Fig. 1 illustrates details of the components of online evaluation system (prototype).

The evaluations process starts with introduction of the evaluation and evaluators need to select the suitable section for them, as an example, if they are a teacher they need to click on teacher section. Before that, teachers need to explore and try to use the specific educational games that being used in the evaluation process. Once the teachers sections have been selected, they need to look at the questions and answer it. Four categories of the questions need to be finish up and they may also type any specific comments and recommendation for each of the section. The evaluations questions are created based on the usability factors that have been selected based on the importance for each characteristics.

\section{Conclusion}

This study of this research is underway and its result may be valuable for specific users, games developers to improves its design, experts evaluators to contribute their professional skills for the improvement of educational games that can be used by various users, teachers to identify the suitability of the educational games and suggest improvement if they think it necessary, parents to know what are the suitable educational games for their children and real users to feel, explore and suggest suitable elements that they think is necessary for their learning process.

The result of this study may also valuable for three reasons. First, the evaluation process involves various types of evaluators, comments and suggestions can be used to improve and enhance the educational games that in development process. Second, the heuristics developed in this study is customizing for evaluation purposes of the interface for educational games. Third the methodology will provide guideline for formative evaluations specifically developed educational games.

\section{References}

Bevan, N. (1995). Measuring usability as quality of use. Software Quality Journal 4, 115-150.

Clanton, C. (1998). An interpreted demonstration of computer game design. Paper presented at the CHI 98 
conference summary on Human factors in computing systems.

Crawford, C. (1984). The Art of Computer Game Design. Berkeley, USA Osborne/McGraw-Hill.

Csikszentmihalyi, M. (1975). Beyond Boredom and Anxiety - The Experience of Play in Work and Games. San Francisco - Washington - London: Jossey-Bass Inc.

Dempsey, J. V., Lucassen, B. A., Haynes, L. L., \& Casey, M. S. (1997). An Exploratory Study of Forty Computer Games.

Desurvire, H. (1994). Faster, Cheaper: Are Usability Inspection Methods as Effective as Empirical Testing? New York: John Wiley \& Sons.

Desurvire, H., Caplan, M., Toth, J.A. (2004). Using heuristics to evaluate the playability of games. Paper presented at the In: Proceedings of the Conference on CHI 2004.

Federoff, M. A. (2002). Heuristics and Usability Guidelines for the Creation and Evaluation of FUN in Video Games. Indiana University, Bloomington.

Garris, R., Ahlers, R., \& Driskell, J. E. (2002). Games, motivation, and learning: A research and practice model. Simulation \& Gaming, 33(4), 441-467.

Gee, J. P. (2003). What video games have to teach us about learning and literacy. New York: Palgrave Macmillan.

Gussin, L. (1995). Evolution of a Genre.

ISO. (1998). Ergonomic Requirements for Office Work with Visual Display Terminals, Part 11: Guidance on Usability. Retrieved. from.

Kasvi, J. (2000). Not Just Fun and Games - Internet Games as a Training Medium. Cosiga - Learning with Computerised Simulation Games. Retrieved 12 April 2007, from http://www.knowledge.hut.fi/people/jkasvi/NJFAG.

Kiili, K. (2005). Content creation challenges and flow experience in educational games: The IT-Emperor case. The Internet and Higher Education, 8(3), 183-198.

Malone, T. W. (1980). What makes things fun to learn? Heuristics for designing instructional computer games. Paper presented at the In: Proceedings of the 3rd ACM SIGSMALL Symposium and the First SIGPC Symposium on Small Systems.

Malone, T. W. (1982). Heuristics for designing enjoyable user interfaces: Lessons from computer games. Norwood, NJ: Ablex Publishing Corporation, .

Maria Virvou, \& Katsionis, G. (2006). On the usability and likeability of virtual reality games for education: The case of VR-ENGAGE. Computers \& Education.

Mary, F., \& Helen, N. (2007). A game design methodology to incorporate social activist themes. Paper presented at the Proceedings of the SIGCHI conference on Human factors in computing systems.

Nielsen, J. (1994). Heuristic evaluation. New York: John Wiley \& Sons.

Nielsen, J., \& Molich, R. (1990). Heuristic Evaluation of User Interfaces. Paper presented at the In Proceedings of Computer Human Interaction.

Pagulayan, R. J., Keeker, K., Wixon, D., Romero, R. L., \& Fuller, T. (2003). User-centered design in games. NJ: Lawrence Erlbaum Associates.

Randel, J. M., Morris, B. A., Wetzel, C. D., \& Whitehill, B. V. (1992). The effectiveness of games for educational purposes: A review of recent research. Simulation \& Gaming, 23(3), 261-276.

Rollings A., \& E., A. (2003). On Game Design. Indiana: New Riders.

Setzer, V. W., \& Duckett, G. E. (2000.). The risks to children using electronic games. Retrieved 15 July 2007 , from $<$ http://www.ime.usp.br/ vwsetzer/videog-risks.html/>

Seungkeun Song and Joohyeon Lee. (2007). Key factors of heuristic evaluation for game design:Towards Massively Multi-player online role-playing game. Int. J. Human-Computer Studies, doi:10.1016/j.ijhcs.2007.1001.1001.

Shackel, B. (1991). Usability - context, framework, design and evaluation. Cambridge: Cambridge University Press. 
Table 1. Heuristics for Evaluating Playability (HEP) (Source:(Desurvire, 2004))

\begin{tabular}{|l|l|}
\hline Usability & Heuristics and Description \\
\hline 1 & Provide immediate feedback for user actions. \\
\hline 2 & The Player can easily turn the game off and on, and be able to save games in different states. \\
\hline 3 & $\begin{array}{l}\text { The Player experiences the user interface as consistent (in control, color, typography, and } \\
\text { dialog design) but the game play is varied. }\end{array}$ \\
\hline 4 & The Player should experience the menu as a part of the game. \\
\hline 5 & Upon initially turning the game on the Player has enough information to get started to play. \\
\hline 6 & $\begin{array}{l}\text { Players should be given context sensitive help while playing so that they do not get stuck or } \\
\text { have to rely on a manual. }\end{array}$ \\
\hline 7 & Sounds from the game provide meaningful feedback or stir a particular emotion. \\
\hline 8 & Players do not need to use a manual to play game. \\
\hline 9 & The interface should be as non-intrusive to the Player as possible. \\
\hline 10 & $\begin{array}{l}\text { Make the menu layers well-organized and minimalist to the extent the menu options are } \\
\text { intuitive. }\end{array}$ \\
\hline 11 & $\begin{array}{l}\text { Get the player involved quickly and easily with tutorials and/or progressive or adjustable } \\
\text { difficulty levels. }\end{array}$ \\
\hline 12 & Art should be recognizable to player, and speak to its function. \\
\hline
\end{tabular}


Table 2. Playability Heuristics for Educational Game (PHEG) (initial phase)

\begin{tabular}{|c|c|}
\hline Usability & Educational Game Usability Heuristics - Interface \\
\hline UI1 & Uses aesthetic and minimalist design \\
\hline UI2 & Maximizes consistency and matches standards \\
\hline UI3 & $\begin{array}{l}\text { The uses of space, color and text are according to the principles of screen } \\
\text { design }\end{array}$ \\
\hline UI4 & The uses of text, color and font follow the principles of readability \\
\hline UI5 & Ensure appropriate use of standard and propriety control \\
\hline UI6 & The interactivity of the game is suitable to learners level \\
\hline UI7 & The integration of presentation means is well-coordinated \\
\hline UI8 & Quality of user interface is acceptable \\
\hline UI9 & $\begin{array}{l}\text { Provide specific and self- identified key for specific task (exit, glossary, } \\
\text { main, objective) }\end{array}$ \\
\hline UI10 & Overall interface of the game is appealing \\
\hline Usability & Educational Game Usability Heuristics - Educational/Pedagogical \\
\hline ED1 & Clear goal and learning objectives \\
\hline ED2 & The activities are interesting and engaging \\
\hline ED3 & The design and the contents are reliable and proven. \\
\hline ED4 & Can be used as self- directed learning tools. \\
\hline ED5 & Support for self- learning skills. \\
\hline ED6 & Medium for learning by doing. \\
\hline ED7 & Considers the individual differences. \\
\hline ED8 & Performance should be an outcome-based. \\
\hline ED9 & Offers the ability to select the level of difficulty in games \\
\hline ED10 & Ability to work in their own pace \\
\hline Usability & Educational Game Usability Heuristics - Content \\
\hline $\mathrm{CO1}$ & Reliable content with correct flow. \\
\hline $\mathrm{CO} 2$ & Clear and understandable structure of contents. \\
\hline $\mathrm{CO} 3$ & Navigation of content is easy and accurate. \\
\hline $\mathrm{CO} 4$ & Supporting materials are sufficient and relevant. \\
\hline $\mathrm{CO} 5$ & Materials are interesting and engaging. \\
\hline $\mathrm{CO6}$ & Players able to understand the learning goal. \\
\hline $\mathrm{CO} 7$ & The content is chunk based on topic and subtopic \\
\hline $\mathrm{CO} 8$ & Major and minor topic is differentiate clearly \\
\hline Usability & Educational Game Usability Heuristics - Multimedia \\
\hline MM1 & Usage of multimedia elements are acceptable \\
\hline MM2 & Combination of multimedia elements are adequate \\
\hline MM3 & The presentation of multimedia elements are well manage \\
\hline MM4 & Suitability of multimedia elements for specific use \\
\hline MM5 & Not too many multimedia element in one screen \\
\hline MM6 & The use of multimedia elements support meaningfully the text provided. \\
\hline MM7 & $\begin{array}{l}\text { The quality of multimedia elements (text, image, animation, video and } \\
\text { sound) used is acceptable. }\end{array}$ \\
\hline MM8 & The uses of multimedia elements enhance the presentation of information. \\
\hline Usability & Educational Game Usability Heuristics - Playability \\
\hline PL1 & Challenge provided are up to the users standard/level \\
\hline PL2 & Users able to strategies \\
\hline PL3 & The pace of the game are in balance \\
\hline PL4 & Players able to control the game \\
\hline PL5 & Progress of the game can be seen at anytime \\
\hline PL6 & Players able to perform to their best ability \\
\hline PL7 & Challenge is adequate - not too easy and not too difficult \\
\hline
\end{tabular}




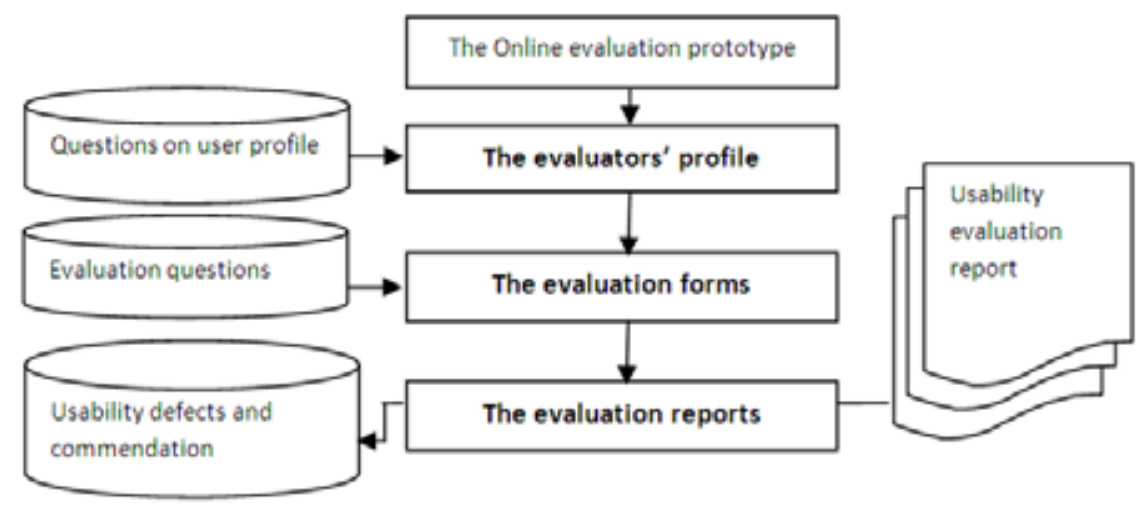

Figure 1. Illustrates details of the components of online evaluation system (prototype). 